\title{
Comparison between the PlusoptiX and IScreen Photoscreeners in Detecting Amblyopic Risk Factors in Children
}

\author{
Jing Grace Wang ${ }^{1}$, Donny W. Suh ${ }^{2,3}$ \\ ${ }^{1}$ Mercy Catholic Medical Center, Philadelphia, USA; ${ }^{2}$ University of Nebraska Medical Center, Omaha, USA; ${ }^{3}$ Wolfe Eye Clinic, \\ West Des Moines, USA. \\ Email: jing.wang@dmu.edu; dowsuh@gmail.com
}

Received October $1^{\text {st }}, 2012$; revised November $3^{\text {rd }}, 2012$; accepted November $10^{\text {th }}, 2012$

\begin{abstract}
Purpose: To compare the accuracy of plusoptiX A08 photoscreener (PPS) and iScreen 3000 photoscreener (IPS) in objectively screening for amblyopic risk factors in children age 5 months to 13 years old. Methods: Cross-sectional study of 148 children who received photoscreenings via PPS and IPS and a comprehensive pediatric ophthalmic examination in our office. Patients were considered to have amblyogenic risk factors based on the AAPOS referral criteria guidelines. Results: 45 percent of patients undergoing a pediatric ophthalmology examination were found to have amblyopia or amblyogenic risk factors. In this study, PPS demonstrated an overall sensitivity of $75.4 \%$, specificity of $68.0 \%$, positive predictive value (PPV) of $67.1 \%$, and negative predictive value (NPV) of $76.1 \%$. However, IPS photoscreener had an overall sensitivity of $66.2 \%$, specificity of $87.6 \%$, PPV of $81.8 \%$, and NPV of $75.5 \%$. Discussion: The accuracy of PPS and IPS was compared in different age groups. The sensitivity and specificity were analyzed according to varied amblyogenic risk factors. The statistic results of this study were compared to those of previous studies, including Vision in Preschoolers (VIP) Study and the Iowa PhotoScreening Program. Conclusion: PPS and IPS proved to be useful tools in the objective vision screening in children. PPS was found to have a higher sensitivity, and IPS showed a higher specificity and PPV in detecting amblyopic risk factors. In conclusion, one device may be more beneficial over the other, depending on the patient population and office settings.
\end{abstract}

Keywords: Amblyogenic Risk Factors; Photoscreeners

\section{Introduction}

Amblyopia is a major cause of visual problems in the developed world [1-3] and the leading cause of blindness in the 20 to 70 year age group [4], affecting $2 \%$ to $5 \%$ of the population [5]. Several studies, including the Prospective Amblyopia Treatment Study, have demonstrated that amblyopia treatment is highly effective when detected and treated in young children [6-12]. Early detection is critical, because there is a window for successful treatment $[6,7,10]$. US Preventive Services Task Force recommends preschool vision screening, beginning at age 3, which is consistent with the American Academy of Pediatrics "Recommendations for Preventive Pediatric Health Care," and Bright Futures Guidelines for Health Supervision of Infants Children and Adolescents [13-15].

Traditional vision screening methods have a relative low compliance due to high over-referral rates, low sensitivity and low specificity [16]. Newer screening methods, including photoscreeners and autorefractors, have been proposed as potential replacements or supplements to traditional screening methods [17-25]. Potential advantages are reduced testing time, increased objectivity of screening, and enhance testability rates in younger children, who may be poorly cooperative with traditional tests. Potential disadvantages are the high initial costs associated with the instruments, and the need with some photoscreeners for external interpretation of screening results [15].

The purpose of this study is to compare the accuracy of plusoptiX A08 photoscreeners (PPS) (plusoptiX Inc., Hillsboro, Beach, FL) and iScreen 3000 photoscreeners (IPS) (iScreen Vision, Cordova, TN) in objectively screening for amblyopic risk factors in children age 5 months to 13 years old.

\section{Methods}

We evaluated the PPS and IPS for detecting amblyopia and amblyogenic risk factors in a pediatric ophthalmolo- 
gy practice in Central Iowa on children age 5 months to 13 years. This is a cross-sectional study of one hundred forty-eight subjects. Before starting this research we received Clinical Research Board approval in West Des Moines, IA. We received a waiver of consent owing to the low risk nature of this research and followed appropriate Health Insurance Portability and Accountability Act of 1996 guidelines.

After retrospective chart review during a 2 months period, all children ages 5 months to 13 years who had a cycloplegic refraction and photoscreening with PPS and IPS devices within 6 months were included. One hundred and forty-eight children were examined consecutively in our office. Each patient had photoscreenings via PPS and IPS and a comprehensive pediatric ophthalmic examination (gold-standard eye examination) during the same visit. The photoscreening was performed by either a certified orthoptist or an ophthalmic technician prior to the patient's examination.

PPS performs refraction at a 1 meter distance under non-cycloplegic conditions. The AAPOS criteria apply to cycloplegic retinoscopy only and therefore should not be directly imported into the device. PPS results were interpreted by the incorporated software. Referral criteria for the PPS were provided by the manufacturer [26] (Table 1). The software allows for customized criteria on the basis of the patient's age. Our study used categories of 5 to 12 months, 12 to 18 months, 18 to 30 months, 30 to 54 months, and 54 to 72 months. For each group there are referral criteria for 5 distinct measurements, including anisometropia, astigmatism, myopia, hyperopia, and anisocoria. Patients were automatically referred from the PPS photoscreening if any of these measurements exceeded our preset values, if both round pupils could not be seen (such as with crying, thrashing, or visually significant ptosis), if the gaze of one eye is eccentric by more than 10 degrees (suggesting a tropia), or if a reading could not be obtained after two attempts.

IPS takes image at a 1 meter distance under non-cycloplegic conditions. Images and information are sent via an Ethernet connection to iScreen Vision Central Analysis for an independent clinical review by a trained technician. A full patient report is returned to the physician by email in less than 24 hours.

Table 1. Referral criteria for the plusoptiX A08.

\begin{tabular}{|c|c|c|c|c|c|}
\hline Age, mo & $\begin{array}{l}\text { Anisome- } \\
\text { tropia, D }\end{array}$ & $\begin{array}{c}\text { Astigmatism, } \\
\text { D }\end{array}$ & $\begin{array}{l}\text { Myopia, } \\
\text { D }\end{array}$ & $\begin{array}{c}\text { Hyperopia, } \\
\text { D }\end{array}$ & $\begin{array}{l}\text { Aniso- } \\
\text { coria, mm }\end{array}$ \\
\hline $5-12$ & $>1.25$ & $>2.00$ & $>2.00$ & $>3.25$ & $\geq 1$ \\
\hline $12-18$ & $>1.00$ & $>1.50$ & $>1.50$ & $>2.00$ & $\geq 1$ \\
\hline $18-30$ & $>1.00$ & $>1.00$ & $>1.25$ & $>2.00$ & $\geq 1$ \\
\hline $30-54$ & $>1.00$ & $>1.00$ & $>1.00$ & $>2.00$ & $\geq 1$ \\
\hline $54-240$ & $>0.75$ & $>0.75$ & $>1.00$ & $>2.00$ & $\geq 1$ \\
\hline
\end{tabular}

The results from both screening methods were compared with comprehensive gold-standard examination findings. Patients were considered to have amblyopia or amblyogenic risk factors in the comprehensive examination on the basis of the American Association of Pediatric Ophthalmology and Strabismus (AAPOS) referral criteria guidelines (Table 2). The complete examination consisted of manual cycloplegic retinoscopy using cyclopentolate hydrochloride $1 \%$, slit lamp examination, cover test, Krimsky test, alternate prism cover test, sensory testing using Titmus Stereogram, and fixation pattern assessment. A cycloplegic refraction was performed that same day or within 6 months. Sensitivity, specificity, positive predictive value and negative predictive value of the instruments were defined for different age groups.

\section{Results}

One hundred and forty-eight patients were included in this study. Each patient had photoscreenings via PPS and IPS and a comprehensive pediatric ophthalmology examination (gold-standard eye examination). 67 patients out of a total of 148 patients $(45 \%)$ were found to have amblyopia or amblyogenic risk factors according to AAPOS guidelines (Table 2). Amblyogenic risk factors detected in the gold-standard eye examination are shown in Figure 1. 20 patients failed the gold-standard exam due to manifest strabismus alone, including 16 esotropia, 2 exotropia and 2 hypertropia. 23 patients failed the exam due to refractive error alone, including 16 hyperopia, 1 myopia and 6 astigmatism. 21 patients failed the exam due to a combination of 2 risk factors; 15 patients have hyperopia and strabismus, 1 patient hyperopia and astigmatism, 3 patients astigmatism and strabismus and 1 patient myopia and strabismus. 3 patients failed the exam due to ptosis.

In this study, PPS demonstrated an overall sensitivity of $75.4 \%$, specificity of $68.0 \%$, positive predictive value (PPV) of $67.1 \%$, and negative predictive value (NPV) of $76.1 \%$. IPS had an overall sensitivity of $66.2 \%$, specificity of $87.6 \%$, PPV of $81.8 \%$, and NPV of $75.5 \%$ (Tables 3 and 4). The comparison of the present study to previous studies was listed in Table 5.

Table 2. Amblyogenic risk factors (AAPOS criteria).

Anisometropia (spherical or cylindrical) $>1.50$
Any manifest strabismus
Hyperopia $>3.5 \mathrm{D}$ in any meridian
Myopia $>3.0 \mathrm{D}$ in any meridian
Any media opacity $>1 \mathrm{~mm}$ in size
Astigmatism $>1.5 \mathrm{D}$ at $90^{\circ}$ or $180^{\circ}$ or $>1.0 \mathrm{D}$ in oblique axis $\left(>10^{\circ}\right.$
eccentric to $90^{\circ}$ or $\left.180^{\circ}\right)$
Ptosis $\leq 1 \mathrm{~mm}$ margin reflex distance
Visual acuity per age-appropriate standards




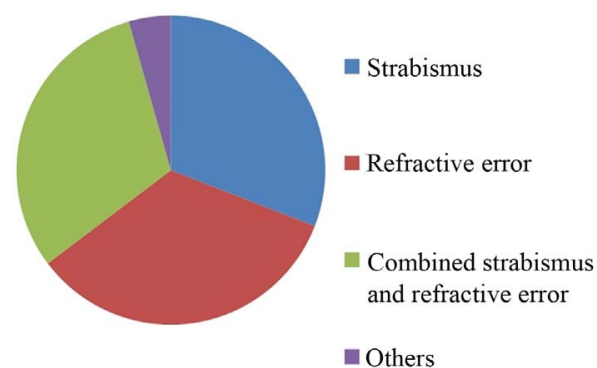

Figure 1. Amblyogenic risk factors detected in gold-standard eye examination.

Table 3. Screening results using plusoptiX A08 and iScreen 3000 .

\begin{tabular}{ccc}
\hline & Results from the gold-standard eye exam \\
\hline $\begin{array}{c}\text { Screening test results } \\
\text { plusoptiX A08 All } \\
\text { patients }\end{array}$ & & \\
Fail & 49 & 24 \\
pass & 16 & 51 \\
Age 0-3 & & \\
Fail & 24 & 16 \\
pass & 10 & 37 \\
Age $\geq 4$ & & \\
Fail & 25 & 8 \\
pass & 6 & 14 \\
iScreen 3000 All & & \\
patients & & 10 \\
Fail & 45 & 71 \\
pass & 23 & \\
Age $0-3$ & & 24 \\
Fail & 19 & 47 \\
pass & 15 & \\
Age $\geq 4$ & & \\
Fail & & \\
pass & & \\
\hline
\end{tabular}

Table 4. Statistic analysis of screening results.

\begin{tabular}{cccccc}
\hline $\begin{array}{c}\text { Screening } \\
\text { test }\end{array}$ & $\begin{array}{c}\text { Patient } \\
\text { population }\end{array}$ & $\begin{array}{c}\text { Sensitivity } \\
(\%)\end{array}$ & $\begin{array}{c}\text { Specificity } \\
(\%)\end{array}$ & PPV (\%) & $\begin{array}{c}\text { NPV } \\
(\%)\end{array}$ \\
\hline \multirow{2}{*}{ plusoptiX } & overall & $75.4(75.9)$ & $68.0(69.1)$ & $\begin{array}{c}67.1 \\
(67.7)\end{array}$ & $76.1(77)$ \\
& & & & 60.0 & 78.7 \\
& age 0 - 3 & $70.5(70.4)$ & $69.8(71.7)$ & $(59.4)$ & $(80.5)$ \\
& age $\geq 4$ & 80.6 & 63.6 & 75.8 & 70.0 \\
iScreen & overall & $66.2(70.5)$ & $87.6(87.8)$ & $\begin{array}{c}81.8 \\
(82.7)\end{array}$ & $\begin{array}{c}75.5 \\
78.3)\end{array}$ \\
& & & & 73.1 & 75.8 \\
& age 0 - 3 & $55.9(63)$ & $87.0(87.2)$ & $(73.9)$ & $(80.4)$ \\
& & & & 80.0 & 75.0 \\
\hline
\end{tabular}

(Excluding subjects who are younger than $1 \mathrm{yr}$ ).
Table 5. Comparison of the present study to previous studies.

\begin{tabular}{|c|c|c|c|c|c|}
\hline $\begin{array}{l}\text { Screening } \\
\text { test }\end{array}$ & Study, year & $\begin{array}{l}\text { Sensitivity } \\
(\%)\end{array}$ & $\begin{array}{c}\text { Specificity } \\
(\%)\end{array}$ & $\begin{array}{l}\text { PPV } \\
(\%)\end{array}$ & $\begin{array}{l}\text { NPV } \\
(\%)\end{array}$ \\
\hline $\begin{array}{c}\text { plusoptiX } \\
\text { A08 }\end{array}$ & $\begin{array}{c}\text { present study, } \\
2011\end{array}$ & 75.4 & 68.0 & 67.1 & 76.1 \\
\hline $\begin{array}{l}\text { Power } \\
\text { refractor }\end{array}$ & VIP, 2004 & 54 & 90 & 70 & 79 \\
\hline $\begin{array}{l}\text { plusoptiX } \\
\text { S04 }\end{array}$ & $\begin{array}{l}\text { Matta et al., } \\
\quad 2009\end{array}$ & 98.9 & 96.1 & 97.9 & \\
\hline $\begin{array}{l}\text { iScreen } \\
3000\end{array}$ & $\begin{array}{c}\text { present study, } \\
2011\end{array}$ & 37 & 94 & 71 & 79 \\
\hline iScreen & VIP, 2004 & 37 & 94 & 71 & 79 \\
\hline MTI & $\begin{array}{l}\text { Matta et al., } \\
\quad 2009\end{array}$ & 83.6 & 90.5 & 94.2 & \\
\hline
\end{tabular}

(Note: Power refractor is a previous model of plusoptiX, and MTI is a previous model of iScreen.)

The accuracy of PPS and IPS was also compared in different age groups. Both screening methods showed a better sensitivity in children age 4 years or older compared to 0 - 3 years $(80.6 \%$ vs. $70.5 \%$ with plusoptiX, and $76.5 \%$ vs. $55.9 \%$ with iScreen). The specificity for both screening tests is similar among different age groups (Table 4). If patients younger than 1 year old were excluded, the overall sensitivity of IPS improved from $66.2 \%$ to $70.2 \%$, and the sensitivity for younger than 3 year old improved from $55.9 \%$ to $63 \%$ (Table 4 ).

Data was further stratified according to different amblyogenic risk factors (Table 6). PPS demonstrated a sensitivity of $40.0 \%$ to detect a single condition of manifest strabismus, and a sensitivity of $81.8 \%$ to detect a single condition of refractive error. With IPS, the sensitivity to detect a single condition of manifest strabismus or refractive error is $66.7 \%$ and $43.5 \%$, respectively. The sensitivity is $100 \%$ for PPS and $90.5 \%$ for IPS when combined conditions exist.

False positive rates were compared in selected milder conditions (Table 7). Among all the 81 patients who passed the gold-standard eye exam, 12 patients have intermittent strabismus or heterophoria, 15 have mild hyperopia, 6 have mild astigmatism and 13 have multiple conditions. False positive rate for each condition with PPS and IPS were listed in Table 7.

\section{Discussion}

We believe that this study is the first report with comparison of PPS and IPS. We conducted a retrospective chart review of 148 patients who received photo- screenings via PPS and IPS and a comprehensive pediatric ophthalmic examination during the same visit. Forty five percent were found to have amblyopia or amblyogenic risk factors according to AAPOS guidelines. Among the amblyogenic risk factors detected in our examination, 
Table 6. Comparison of sensitivity for different amblyogenic risk factors (interpretation for FN results).

\begin{tabular}{ccc}
\hline $\begin{array}{c}\text { Amblyogenic risk factors } \\
\text { (\# of patient) }\end{array}$ & PlusoptiX & iScreen \\
\hline Manifest strabismus (21) & $40.0 \%$ & $66.7 \%$ \\
Refractive error (23) & $81.8 \%$ & $43.5 \%$ \\
Combined condition (21) & $100 \%$ & $90.5 \%$ \\
Overall & $75.4 \%$ & $66.2 \%$ \\
\hline
\end{tabular}

Table 7. Comparison of false positive rate for selected conditions (interpretation for FP result and the specificity).

\begin{tabular}{ccc}
\hline $\begin{array}{c}\text { Selected condition } \\
\text { (\# of patient) }\end{array}$ & PlusoptiX & iScreen \\
\hline $\begin{array}{c}\text { Intermittent strabismus or } \\
\text { heterophoria (12) }\end{array}$ & $16.7 \%$ & $8.3 \%$ \\
Mild hyperopia (15) & $23.1 \%$ & $13.3 \%$ \\
Mild astigmatism (6) & $80.0 \%$ & $16.7 \%$ \\
Combined condition (13) & $66.7 \%$ & $30.8 \%$ \\
Overall & $32.4 \%$ & $12.5 \%$ \\
\hline
\end{tabular}

(Definition: mild hyperopia $\geq 2.0 \mathrm{D}$, mild astigmatism $\geq 1.0$ at $90^{\circ}$ or $180^{\circ}$ or $\geq 0.75$ at oblique axis).

hyperopia, esotropia or a combination of both are the most frequently encountered amblyopic risk factors.

31 studies evaluated the diagnostic accuracy of various preschool vision screening tests [15]. The Vision in Preschoolers (VIP) study is the largest study so far to directly compare the diagnostic accuracy of different individual screening test, including Power Refractor (previous model of plusoptiX) and iScreen $[24,25]$. The statistical analysis result was shown in Table 5. Iowa Photoscreening Program reported a study with the largest number of participants $(147,809)$ using MTI PhotoScreener over a 9-year period [19]. The sensitivity and specificity of the MTI PhotoScreener was not evaluated in this study, but was predetermined to have a sensitivity of $81.8 \%$ and a specificity of $90.6 \%$ in a previous study [27]. The overall PPV is $94.2 \%$ for the MTI Photo- Screener over the 9 years of the program. Differences between studies in the patient populations, prevalence of target diseases, model of the devices, and screening thresholds applied make it difficult to reach strong conclusions about how they compare with one another.

In the present study, PPS was found to have a higher sensitivity, and IPS showed a higher specificity and PPV in detecting amblyopic risk factors (Tables 4 and 5). The difference in sensitivity and specificity may be explained by the differences in the mechanism of these 2 devices. The IPS consists of an off-axis photorefractor connected to a laptop computer that binocularly measures refractive error in one meridian and measures eye alignment. The refractive error was determined based on the red reflex images of the eyes. PPS is a binocular autorefractor which can detect refractive error down to $0.25 \mathrm{D}$ and significant strabismus.

Evidence on the comparative accuracy of preschool vision tests in different age groups among children ages 1 to 5 years is limited. Four studies found no clear differences in the diagnostic accuracy of various screening tests in preschool-aged children stratified according to age [15]. In this study, the accuracy of PPS and IPS photoscreeners was compared in age 0 - 3 years vs. 4 years or older (Table 4). Both screening methods showed a better sensitivity in children age 4 years or older, with more dramatic difference in IPS results. The specificity is similar in different age groups. This result demonstrated a higher false negative rate in the $0-3$ years old age group, which may be explained by less cooperativeness in younger patients during the tests. When patients younger than 1 year old were excluded, the sensitivity of IPS was improved $7.1 \%$ in $0-3$ year old age group. Statistical analysis for PPS was not affected by this exclusion. The results from our study suggest that PPS is a more sensitive test in comparison to IPS in detecting amblyogenic risk factors, with more superiority in patients age $0-3$ years.

In order to answer the question of why false negative results exist, we further stratified the data according to different amblyogenic risk factors (Table 6). PPS demonstrated a lower sensitivity to detect manifest strabismus, with a sensitivity of $40.0 \%$ compared to $66.7 \%$ in IPS results. However, PPS has a higher sensitivity to detect refractive error, with a sensitivity of $81.8 \%$ compared to $43.5 \%$ in IPS results. The sensitivity increased significantly when combined conditions exist, $100 \%$ for PPS and $90.5 \%$ for IPS.

To explain why machines failed some patients who have milder disease that do not meet the AAPOS referral criteria, "mild conditions" was defined in Table 7. PPS had a highest false positive rate $(80 \%)$ when mild astigmatism exists. Coexistence of 2 or more mild conditions causes high false positive rate, $66.7 \%$ with PPS and $30.8 \%$ with IPS. False positive rate is in a reversed relationship to specificity. This result suggests that PPS has a lowest specificity when mild astigmatism or combined mild conditions exist. Further study with a larger patient number is needed to confirm the above statement.

\section{Conclusion}

The PPS and IPS photoscreeners proved to be useful tools in the objective vision screening in children. PPS was found to have a higher sensitivity, and IPS showed a higher specificity and PPV in detecting amblyopic risk factors. PPS demonstrated a lower sensitivity in detecting manifest strabismus, and an excellent sensitivity in detecting refractive error. On the contrary, IPS had a higher 
sensitivity in detecting manifest strabismus than refracttive error. With mild astigmatism or coexistence of 2 or more mild conditions, PPS showed a higher false positive rate, i.e., lower specificity. In conclusion, one device may be more beneficial over the other, depending on the patient population and office settings. Despite each device has its own strengths and weaknesses, they both are found to be very useful tools in the objective vision screening in children.

\section{REFERENCES}

[1] M. I. Ehrlich, R. D. Reinecke and K. Simons, "Preschool Vision Screening for Amblyopia and Strabismus. Programs, Methods, Guidelines, 1983," Survey of Ophthalmology, Vol. 28, No. 3, 1983, pp. 145-163. doi:10.1016/0039-6257(83)90092-9

[2] K. Simons, "Preschool Vision Screening: Rationale, Methodology and Outcome," Survey of Ophthalmology, Vol. 41, No. 1, 1996, pp. 3-30. doi:10.1016/S0039-6257(97)81990-X

[3] K. Attebo, P. Mitchell, R. Cumming, W. Smith, N. Jolly and R. Sparkes, "Prevalence and Causes of Amblyopia in an Adult Population," Ophthalmology, Vol. 105, No. 1, 1998, pp. 154-159. doi:10.1016/S0161-6420(98)91862-0

[4] C. Powell and S. R. Hatt, "Vision Screening for Amblyopia in Childhood," Cochrane Database of Systematic Reviews, No. 3, 2009, Article ID: CD005020.

[5] J. R. Thompson, G. Woodruff, F. A. Hiscox, N. Strong and C. Minshull, "The Incidence and Prevalence of Amblyopia Detected in Childhood," Public Health, Vol. 105, No. 6, 1991, pp. 455-462. doi:10.1016/S0033-3506(05)80616-X

[6] M. Eibschitz-Tsimhoni, T. Friedman, J. Naor, N. Eibschitz and Z. Friedman, "Early Screening for Amblyogenic Risk Factors Lowers the Prevalence and Severity of Amblyopia," Journal of AAPOS, Vol. 4, No. 4, 2000, pp. 194-199. doi:10.1067/mpa.2000.105274

[7] J. H. Groenewoud, A. M. Tjiam, V. K. Lantau, W. C. Hoogeveen, J. T. de Faber, R. E. Juttmann, H. J. de Koning and H. J. Simonsz, "Rotterdam AMblyopia Screening Effectiveness Study: Detection and Causes of Amblyopia in a Large Birth Cohort," Investigative Ophthalmology \& Visual Science, Vol. 51, No. 7, 2010, pp. 34763484. doi:10.1167/iovs.08-3352

[8] The Pediatric Eye Disease Investigator Group, "A Randomized Trial of Atropine vs. Patching for Treatment of Moderate Amblyopia in Children," Archives of Ophthalmology, Vol. 120, No. 3, 2002, pp. 268-278. doi:10.1001/archopht.120.3.268

[9] M. X. Repka, R. T. Kraker, R. W. Beck, J. M. Holmes, S. A. Cotter, E. E. Birch, W. F. Astle, D. L. Chandler, J. Felius, R. W. Arnold, D. R. Tien and S. R. Glaser, "A Randomized Trial of Atropine vs. Patching for Treatment of Moderate Amblyopia: Follow-Up at Age 10 Years," Archives of Ophthalmology, Vol. 126, No. 8, 2008, pp. 10391044. doi:10.1001/archopht.126.8.1039

[10] V. G. Kirk, M. M. Clausen, M. D. Armitage and R. W.
Arnold, "Preverbal Photoscreening for Amblyogenic Factors and Outcomes in Amblyopia Treatment: Early Objective Screening and Visual Acuities," Archives of Ophthalmology, Vol. 126, No. 4, 2008, pp. 489-492. doi:10.1001/archopht.126.4.489

[11] R. G. Teed, C. M. Bui, D. G. Morrison, R. L. Estes and S. P. Donahue, "Amblyopia Therapy in Children Identified by Photoscreening," Ophthalmology, Vol. 117, No. 1, 2010, pp. 159-162. doi:10.1016/j.ophtha.2009.06.041

[12] K. Taylor and S. Elliott, "Interventions for Strabismic Amblyopia," Cochrane database of systematic reviews, No. 8, 2011, Article ID: CD006461.

[13] S. P. Donahue and J. B. Ruben, et al., "US Preventive Services Task Force Vision Screening Recommendations," Pediatrics, Vol. 127, No. 3, 2011, pp. 569-570. doi:10.1542/peds.2011-0020

[14] R. Chou, T. Dana and C. Bougatsos, "Screening for Visual Impairment in Children Ages 1-5 Years: Systematic Review to Update the 2004 U.S. Preventive Services Task Force Recommendation," Agency for Healthcare Research and Quality (US), Rockville, 2011.

[15] A. Kemper, R. Harris, T. A. Lieu, C. J. Homer and B. L. Whitener, "Screening for Visual Impairment in Children Younger than Age 5 Years: A Systematic Evidence Review for the U.S. Preventive Services Task Force," Agency for Healthcare Research and Quality (US), Rockville, 2004.

[16] T. C. Wall, W. Marsh-Tootle, H. H. Evans, C. A. Fargason, C. S. Ashworth and J. M. Hardin, "Compliance with Vision-Screening Guidelines among a National Sample of Pediatricians," Ambulatory Pediatrics, Vol. 2, No. 6, 2002, pp. 449-455. doi:10.1367/1539-4409(2002)002<0449:CWVSGA $>2.0$. $\underline{\mathrm{CO} ; 2}$

[17] P. Y. Tong, E. Enke-Miyazaki, R. E. Bassin, J. M. Tielsch, D. R. Stager Sr., G. R. Beauchamp and M. M. Parks, "Screening for Amblyopia in Preverbal Children with Photoscreening Photographs. National Children's Eye Care Foundation Vision Screening Study Group," Ophthalmology, Vol. 105, No. 5, 1998, pp. 856-863.

[18] Committee on Practice and Ambulatory Medicine and Section on Ophthalmology, "Use of Photoscreening for Children's Vision Screening," Pediatrics, Vol. 109, No. 3, 2002, pp. 524-525. doi:10.1542/peds.109.3.524

[19] S. Q. Longmuir, W. Pfeifer, A. Leon, R. J. Olson, L. Short and W. E. Scott, "Nine-Year Results of a Volunteer Lay Network Photoscreening Program of 147,809 Children Using a Photoscreener in Iowa," Ophthalmology, Vol. 117, No. 10, 2010, pp. 1869-1875. doi:10.1016/j.ophtha.2010.03.036

[20] N. S. Matta, R. W. Arnold, E. L. Singman and D. I. Silbert, "Can a Photoscreener Help Us Remotely Evaluate and Manage Amblyopia?" American Orthoptic Journal, Vol. 61, No. 1, 2011, pp. 124-127. doi:10.3368/aoj.61.1.124

[21] A. S. A. Moghaddam, A. Kargozar, M. Zarei-Ghanavati, M. Najjaran, V. Nozari and M. T. Shakeri, "Screening for Amblyopia Risk Factors in Preverbal Children Using the Plusoptix Photoscreener: A Cross-Sectional Population- 
Based Study," British Journal of Ophthalmology, 2011,

[22] S. P. Donahue, J. D. Baker, W. E. Scott, P. Rychwalski, D. E. Neely, P. Tong, D. Bergsma, D. Lenahan, D. Rush, K. Heinlein, R. Walkenbach and T. M. Johnson, "Lions Clubs International Foundation Core Four Photoscreening: Results from 17 Programs and 400,000 Preschool Children," Journal of AAPOS, Vol. 10, No. 1, 2006, pp. 44-48. doi:10.1016/j.jaapos.2005.08.007

[23] N. S. Matta, E. L. Singman and D. I. Silbert, "Performance of the Plusoptix S04 Photoscreener for the Detection of Amblyopia Risk Factors in Children Aged 3 to 5," Journal of AAPOS, Vol. 14, No. 2, 2010, pp. 147-149.

[24] S. P. Donahue, R. W. Arnold and J. B. Ruben, "Preschool Vision Screening: What Should We Be Detecting and how Should We Report It? Uniform Guidelines for Reporting Results of Preschool Vision Screening Studies," Journal of AAPOS, Vol. 7, No. 5, 2003, pp. 314-316.
[25] P. Schmidt, M. Maguire, V. Dobson, G. Quinn, E. Ciner, L. Cyert, M. T. Kulp, B. Moore, D. Orel-Bixler, M. Redford and G. S. Ying, "Comparison of Preschool Vision Screening Tests as Administered by Licensed Eye Care Professionals in the Vision in Preschoolers Study," Ophthalmology, Vol. 111, No. 4, 2004, pp. 637-650.

[26] M. M. Clausen and R. W. Arnold, "Pediatric eye/vision screening. Referral Criteria for the Pedia Vision plus Optix S 04 Photoscreener Compared to Visual Acuity and Digital Photoscreening. Kindergarten Computer Photoscreening," Binocular Vision and Strabismus Quarterly, Vol. 22, No. 2, 2007, pp. 83-89.

[27] W. L. Ottar, W. E. Scott and S. I. Holgado, "Photoscreening for Amblyogenic Factors," Journal of Pediatric Ophthalmology and Strabismus, Vol. 32, No. 5, 1995, pp. 289-295. 